\title{
A report of 2 patients with transient blindness following Le Fort I osteotomy and a review of past reported cases
}

\author{
Philip Mathew, Hirji Sorab Adenwalla, Puthucode V Narayanan, Emily Nyamu \\ Department of Plastic Surgery and Burns, The Charles Pinto Centre for Cleft Lip, Palate and Craniofacial Anomalies, Jubilee \\ Mission Medical College and Research Institute, Thrissur, Kerala, India
}

Address for correspondence: Dr. Philip Mathew, Jubilee Mission Medical College and Research Institute, Thrissur, Kerala, India. E-mail: charlespinto102@gmail.com

\section{ABSTRACT}

Blindness following a LeFort I osteotomy is a rare but extremely serious complication. Ten cases have been reported to date. None of these patients recovered vision. Optic neuropathy is believed to be the cause but the exact mechanism has not been settled. We report the first, and the only two, documented cases of complete loss of vision that recovered subsequently. The first patient was a 19 -year-old male with repaired bilateral cleft lip and palate. He developed loss of vision in the right eye on the second postoperative day. The second patient was a 22-year-old male with repaired unilateral cleft lip and palate. He developed complete loss of vision in the left eye on the day of surgery. Both these patients underwent ongoing studies, which did not show any abnormalities. Both were treated with methylprednisolone. Both the patients gradually showed improvement in their vision. The first patient recovered normal vision several months postoperatively. The second patient's vision improved to $4 / 60$ by 4 months postoperatively. We discuss the probable mechanisms of optic nerve injury and also the possible reasons why sight was restored in these patients. This is a rare but serious complication following a fairly common procedure. Through this article we wish to create an awareness of this complication and also a possible way of avoiding such a disaster.

\section{KEY WORDS}

Blindness, complications, hypotensive anaesthesia, LeFort I osteotomy,maxillary regression

\section{INTRODUCTION}

lindness following a Le Fort I osteotomy, though rare, is an extremely serious complication. Ten cases have been reported to date. (Laniganet al., Bendor-Samuel et al.,Girotto et al., Wilson et al., Lo et al., Cruz et al., Cheng et al..). ${ }^{[1-7]}$ It may occur in isolation or

\begin{tabular}{|l|l|}
\hline \multicolumn{2}{|c|}{ Access this article online } \\
\hline Quick Response Code: & Website: \\
\hline & www.ijps.org \\
\hline
\end{tabular}

with other ophthalmic or intracranial complications. These include: Lachrymal gland injuries; cranial nerve III, IV and VI palsies; traumatic aneurysms; and arteriovenous fistulae (Lanigan et al., Girotto et al., Cruz et al., Steel and

\begin{abstract}
This is an open access article distributed under the terms of the Creative Commons Attribution-NonCommercial-ShareAlike 3.0 License, which allows others to remix, tweak, and build upon the work non-commercially, as long as the author is credited and the new creations are licensed under the identical terms.
\end{abstract}

For reprints contact: reprints@medknow.com

How to cite this article: Mathew P, Adenwalla HS, Narayanan PV, Nyamu E. A report of 2 patients with transient blindness following Le Fort I osteotomy and a review of past reported cases. Indian J Plast Surg 2015;48:297-300. 
Cope)..$^{[1,3,6,8]}$ It is generally agreed that optic neuropathy is the mechanism that leads to loss of vision in a Le Fort I osteotomy, but exactly how this occurs in an elective surgery is a question of debate. Direct injury to the nerve from atypical fractures of the base of skull or orbital walls has been found to account for only 3 of the 10 reported cases in the literature (Lanigan et al., Bendor-Samuel et al., Cruz et al.), ${ }^{[1,2,6]}$ while indirect trauma to the optic nerve or its blood supply has been considered in the other 7 cases (Lanigan et al. Girotto et al.,Wilson et al., Lo et al. Cheng et al.). . ${ }^{[1,3,4,5,7]}$

We report the first 2 documented cases of complete loss of vision that was restored, following Le Fort I osteotomies. The reported cases were in cleft patients and were presumably straightforward cases with no untoward difficulties intraoperatively. In one case, full vision was regained, while near-complete vision has been recovered in the second, more recent case.

\section{CASE REPORT}

\section{Case 1}

A 19-year-old male with bilateral cleft lip and palate presented to the centre in February 2006 for correction of his maxillary regression. The patient's medical history was unremarkable. A Le Fort I osteotomy with advancement was performed under controlled hypotensive anaesthesia with the mean arterial pressure maintained at about $70 \mathrm{mmHg}$. The duration of hypotensive anaesthesia was approximately $20 \mathrm{~min}$. The osteotomy, pterygoid dysjunction and downfracture of the maxilla were done without any difficulty. The estimated blood loss for the procedure was $500 \mathrm{~mL}$ and the duration of surgery was $90 \mathrm{~min}$. His recovery from anaesthesia was uneventful.

On the second postoperative day, the patient complained of loss of vision in the right eye. On examination, there was no perception of light in the right eye, while the visual acuity for the left eye was 6/6.The right pupil was sluggishly reactive to light. The patient was immediately started on intravenous methylprednisolone $500 \mathrm{mg}$, twice daily. Meanwhile, an emergent computed tomography (CT) scan of the orbits, base of skull and brain, and Doppler study of the carotid and vertebral arteries were done.

Except for opacities seen in all the paranasal sinuses suggestive of haemorrhage and the left pterygoid separation that had occurred anterior to the pterygomaxillary fissure, the CT scans were normal. The Doppler study of the carotid and vertebral arteries was also normal [Figure 1a and $\mathrm{b}$ ].

The patient's vision in the right eye began to improve gradually from hand movements on the $11^{\text {th }}$ postoperative day, to a visual acuity of 6/9 by 1 month postoperatively. Fundus examination later showed disc pallor in the right eye, with normal findings in the left eye. A diagnosis of ischaemic optic neuropathy was made. Several months postoperatively, $6 / 6$ vision was reported for the right eye and has remained so, to date.

\section{Case 2}

A 22-year-old male patient with unilateral cleft lip and palate presented with maxillary regression. His medical history was not significant. A Le Fort I osteotomy with advancement was performed in August 2012.

The procedure was uneventful and the pterygoid dysjunction and down-fracture were done without any difficulty. Controlled hypotensive anaesthesia was given for less than $20 \mathrm{~min}$, with the mean arterial pressure maintained at $70 \mathrm{mmHg}$.The duration of surgery was $45 \mathrm{~min}$ and the estimated blood loss was approximately $700 \mathrm{~mL}$.

Postoperatively in the recovery room, he complained of complete loss of vision in the left eye. He was immediately started on intravenous methylprednisolone $1 \mathrm{~g}$, twice daily. CT scans and an urgent ophthalmology consultation were requested immediately. Eye examination revealed

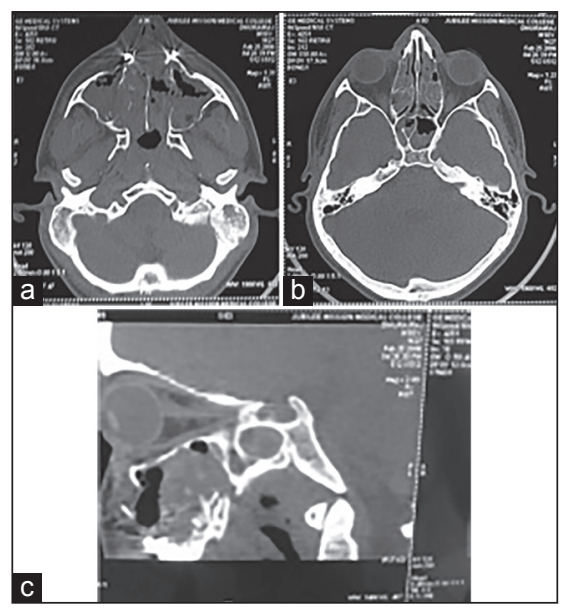

Figure 1:( $a$ and $b)$ Coronal section of the first patient showing blood in the spheno-ethmoidal and maxillary sinuses (c) Sagittal section of the first patient showing intact optic canal 
defective vision in the left eye, while the right eye was normal. The left pupil was sluggishly reactive to light.

CT scans showed no atypical fractures to the base of skull or orbits, but showed opacities in the spheno-ethmoidal air cells. The pterygoid dysjunction had occurred anterior to the pterygomaxillary fissure on the right side. The carotid Doppler report was normal [Figure 2a and b].

The patient's left eye vision improved gradually, with a visual acuity of $1 / 60$ on the $6^{\text {th }}$ postoperative day to $4 / 60$ by 4 months postoperatively. Disc pallor of the left eye was noted on fundoscopy 1 month postoperatively, and a diagnosis of ischaemic optic neuropathy was made.

\section{DISCUSSION}

The complication of blindness following an elective surgery is indeed devastating to both the patient and the surgeon, especially when one cannot explain to the patient exactly how it has occurred. Fortunately, blindness is a rare complication. We report 2 cases of blindness out of 690 Le Fort I surgeries done from 1996 to 2012 by the same surgeon, for an overall incidence of $0.29 \%$. Lanigan et al. ${ }^{[1]}$ reported an incidence of $0.25 \%$ in a survey of North American oral and maxillofacial surgeons, while Lo et al. ${ }^{[5]}$ reported an incidence of $2.1 \%$ for a centre in Taiwan.

In the 7 cases in literature, and in our 2, where unfavourable fractures are absent, adverse transmission of forces to the base of skull during pterygoid separation and downfracture has been proposed as the mechanism of injury (Cruz et al., Polley). ${ }^{[6,9]}$ Transmitted forces have

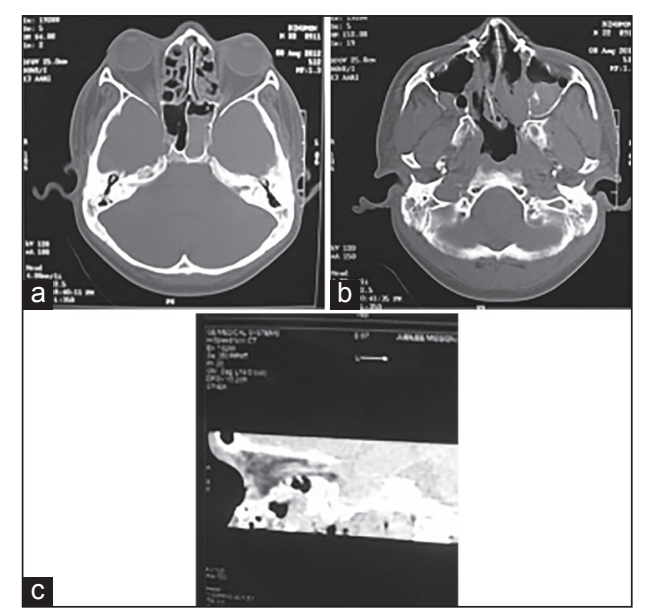

Figure 2: $(a$ and $b$ ) Coronal section showing blood in the spheno-ethmoidal and maxillary sinuses of the second patient (c) Sagittal section of second patient showing intact optic canal been postulated to cause contusion or contrecoup type injuries to the nerve or compression of the nerve from haemorrhage and/or oedema around the optic canal, causing ischaemia of the nerve. It has also been considered that hypoperfusion of the optic nerve due to the controlled systemic hypotension might have a significant role in causing blindness (Lanigan et al. Cheng et al..). ${ }^{[1,7]}$

Injury to the ophthalmic artery from transmitted forces could be responsible for the haemorrhage within the spheno-ethmoidal sinuses in the CT scans of both our cases. The resultant hypoperfusion to the nerve, made worse by the hypotensive anaesthesia, may have caused the ischaemic optic neuropathy that led to unilateral loss of vision. We believe that loss of vision occurred unilaterally because the forces transmitted to the nerves and therefore the degree of injury inflicted on the nerves was unequal, as evidenced by the fracture pattern seen following both our osteotomies. The fractures had occurred anterior to the pterygomaxillary fissure, Type F separation (Ueki et al.), ${ }^{[10]}$ on the opposite side of the affected nerves. Lanigan et al., ${ }^{[1]}$ stated that evidence of spheno-ethmoidal sinus haemorrhage should make one suspicious of the possibility of optic nerve injury, though they did not elucidate on the mechanism of injury.

We believe that the optic nerve and the ophthalmic artery suffer some degree of injury following this elective surgery due to their proximity to the surgical site. However, from our 2 cases, it appears that the nerve can recover from this insult, as long as it is not exposed to additional and prolonged ischaemic injury from controlled systemic hypotensive anaesthesia. Fortunately for our 2 cases, the duration of hypotensive anaesthesia was short and this was perhaps the reason the blindness was reversible. Lanigan et al., ${ }^{[1]}$ reported a case of blindness where the patient had been on hypotensive anaesthesia for $3 \mathrm{~h}$; Lo et al ${ }^{[5]}$ reported that both their cases had been under hypotensive anaesthesia for $75 \mathrm{~min}$ and $95 \mathrm{~min}$; and Wilson et al., ${ }^{[4]}$ though they did not mention the duration of hypotensive anaesthesia, had a 14-h surgery with a lowest recorded blood pressure (BP) of $80 / 40$. Cheng et al. ${ }^{[7]}$ also reported a case of blindness where hypotensive anaesthesia had been used for $8 \mathrm{~h}$. All these patients suffered irreversible blindness.

Controlled hypotensive anaesthesia in isolation does not cause blindness; it seems to aggravate the insult to an already injured nerve. This is evidenced by Kumar et al. $(2004)^{[13]}$, who reported a case of blindness following 
spinal surgery due to compression of the globe by the head rest in the prone position. Cheng et al. ${ }^{[7]}$ also reported a case of blindness where the effects of a hypoplastic carotid artery may have been made worse by hypotensive anaesthesia following Le Fort osteotomy. It has also been shown from animal studies that the optic nerve will not recover from ischaemia of over $60 \mathrm{~min}$ (Yoon and Marmor, Tsukahara et al.). ${ }^{[11,12]}$ The duration of tolerable ischaemia to the optic nerve is quite possibly much lower in humans.

We therefore strongly recommend that hypotensive anaesthesia be avoided for this procedure or, if used at all, be used for a very short period of time. Proper surgical technique should also be employed to avoid unfavourable fractures and excessive haemorrhage, hence circumventing the need for hypotensive anaesthesia. It is also suggested that all patients undergoing Le Fort osteotomies undergo a preoperative ophthalmic assessment of vision.

\section{Financial support and sponsorship}

Nil.

\section{Conflicts of interest}

There are no conflicts of interest.

\section{REFERENCES}

1. Lanigan DT, Romanchuk K, Olson CK. Opthalmic complications associated with orthognathic surgery. J Oral Maxillofac Surg 1993;51:480-94.
2. Bendor-Samuel R, Chen YR, Chen PK. Unusual complications of the Le Fort I osteotomy. Plast Reconstr Surg 1995;96: 1289-97.

3. Girotto JA, Davidson J, Wheatley M, Redett R, Muehlberger T, Robertson B, et al. Blindness as a complication of Le Fort osteotomies: Role of atypical fracture patterns and distortions of the optic canal. Plast Reconstr Surg 1998;102:1409-23.

4. Wilson M, Maheshwari P, Stokes K, Wheatley MJ, McLoughlin S, Talbot M, et al. Secondaryfractures of the Le Fort I osteotomy. Opthal Plast Reconstr Surg 2000;16:258-70.

5. Lo LJ, Hung KF, Chen YR. Blindness as a complication of the Le Fort I osteotomy for maxillary distraction. Plast Reconstr Surg 2002;109:688-700.

6. Cruz AA, dos Santos AC. Blindness after Le Fort I osteotomy: A possible complication associated with pterygomaxillary separation. J Craniomaxillofac Surg 2006;34:210-6.

7. Cheng HC, Chi LH, Wu JY, Hsieh TT, Pemg BY. Blindness and basal ganglia hypoxia as a complication of Le Fort I osteotomy attributable to hypoplasia of the internal carotid artery. A case report. Oral Surg Oral Med Oral Pathol Oral Radiol Endod 2007;104:e27-33.

8. Steel BJ, Cope MR. Unusual and rare complications of orthognathic surgery: A literature review. J Oral Maxillofac Surg 2012;70:1678-91.

9. Polley JW. Blindness as a complication of Le Fort I osteotomy for maxillary distraction - discussion. Plast Reconstr Surg 2002;109:699-700.

10. Ueki K, Hashiba Y, Marukawa K, Okabe K,Alam S, Nakagawa K, et al. Assessment of Pterygomaxillary Separation in Le Fort I Osteotomy in Class III Patients. J Oral Maxillofac Surg 2009;67:833-9.

11. Yoon YH, Marmor MF. Dextromethorphan protects retina against ischemic injury in vivo. Arch Opthalmol 1989;107:409-11.

12. Tsukahara Y, Blair NP, Eappen D, Moy J, Takahashi A, Shah GK, et al. Ketamine suppresses ischemic injury in the rabbit retina. Invest Opthalmol Vis Sci 1992;33:1822-5.

13. Girotto JA, Davidson J, Wheatly M, Redett R, Muehlberger T, Robertson B, et al. Blindness as a complication of Le Fort osteotomies: Role of atypical fracture patterns and distortion of the optic canal. Plast Reconstr Surg 1998;102:1409-23. 